\title{
Adipose Derived Tissue Engineered Heart Valve
}

\author{
Frese $\mathrm{L}^{1,2}$, Sanders $\mathrm{B}^{3}$, Beer GM${ }^{4}$, Weber $\mathrm{B}^{1,2}$, Driessen-Mol $\mathrm{A}^{3}$, Baaijens FPT ${ }^{3}$ and Hoerstrup SP ${ }^{1,2,5 *}$ \\ ${ }^{1}$ University Hospital and University Zurich, Division of Surgical Research, Zurich, Switzerland \\ ${ }^{2}$ Swiss Center for Regenerative Medicine, University Hospital, Zurich, Switzerland \\ ${ }^{3}$ Eindhoven University of Technology, Department of Biomedical Engineering, Eindhoven, The Netherlands \\ ${ }^{4}$ Clinic for Plastic, Aesthetic and Reconstructive Surgery, Zurich, Switzerland \\ ${ }^{5}$ Clinic for Cardiovascular Surgery, University Hospital, Zurich, Switzerland
}

\begin{abstract}
Introduction: A major challenge associated with heart valve tissue engineering is the in vitro creation of mature tissue structures compliant with native valve functionality. Various cell types have been investigated for heart valve tissue engineering. In addition to prenatal, umbilical cord- and vascular-derived cells, mesenchymal stem cells (MSCs) have gained large interest for tissue engineering purposes, because of their broad differentiation potential. However, bone marrow derived MSCs require a highly invasive harvesting procedure and decline in both cell number and differentiation potential proportionally with the donor's age. In contrast, adipose derived stem cells (ADSCs) represent an interesting alternative. The ease of repeated access to subcutaneous adipose tissue as well as the less invasive donation procedures provide clear advantages. Therefore, this study investigated the suitability of ADSCs as alternative cell source for tissue engineered heart valves (TEHVs).
\end{abstract}

Methods: Human ADSCs were seeded on TEHV-scaffolds $(n=11)$ made of nonwoven polyglycolic acid coated with poly-4-hydroxybutyrate. TEHVs were cultivated in diastolic-pulse-duplicator-bioreactor systems and subsequently seeded with a superficial layer of ADSC-derived endothelial cells. Quantitative assessment of extracellular matrix composition of the TEHV-leaflets was performed with biochemical analyses for sulphated glycosaminoglycans, hydroxyproline and DNA content. Microstructural evaluation was performed on representative samples of the TEHVleaflets by (immuno-)histochemistry and scanning electron microscopy. The mechanical properties of the ADSC derived TEHV-leaflets were characterized by biaxial tensile tests.

Results: ADSC-derived TEHV-leaflets showed a homogenous vital cell distribution throughout the whole leaflet structure that consisted of large amounts of glycosaminoglycans and collagen and was endothelialized. Furthermore, the mechanically stable matrix of the ADSC-derived TEHVs showed a stiffness range in the right order of magnitude for heart valve applications.

Conclusion: Human ADSCs represent a promising alternative autologous mesenchymal cell source for TEHVs that is of large clinical relevance due to their easy accessibility, efficient proliferation and excellent tissue formation capacities.

Keywords: Heart valve replacement; Cardiovascular tissue engineering; Mesenchymal stem cells; Adipose derived stem cells; Fat tissue; Regenerative medicine

\section{Introduction}

Heart and other cardiovascular-associated diseases rank among the foremost causes of death worldwide. More people currently suffer from cardiovascular diseases (CVD) than from any other disease. According to the World Health Organization (WHO), approximately 17.3 million people died from CVD in 2008. The number of affected individuals is expected to progressively increase in the decades to come. Cardiac dysfunction can be due to congenital or acquired heart diseases, which often impair the heart valves. Approximately 280'000 heart valve replacements are required annually worldwide [1]. Considering the aging of the world population, this number is anticipated to triple to over 850000 within five decades [2].

Despite continuous progress in treatment, an ideal therapy has not yet been found making this a field of disease with high medical relevance. Current best clinical practice consists of surgical prosthetic heart valve replacement [3-5]. These valves can be either a mechanical, biological allogenic [6,7] or xenogenic [8] prosthesis. Unfortunately these replacements suffer from disadvantages associated with clinical limitations such as necessary lifelong anti-coagulation treatment, risk of immunogenic reactions or adverse reaction such as extensive calcification and degradation giving rise to possible reoperations
$[9,10]$. Moreover, these prostheses lack the ability of both growth and remodeling.

Heart valve tissue engineering represents a promising solution to overcome these limitations of current heart valve substitutes. A major focus in heart valve tissue engineering is the in vitro creation of mature tissue structures compliant with native valve functionality. Various cell types have been investigated for their suitability for heart valve tissue engineering including high remodeling capacity of the Extracellular Matrix (ECM), including prenatal cells [11-13], umbilical cord [1416] and vascular derived cells [17-19]. Furthermore the observed multipotency of adult Mesenchymal Stem Cells (MSCs) including their ability to differentiate into cells found in the adult heart, such as

*Corresponding author: Simon P Hoerstrup, Swiss Center of Regenerative Medicine and Clinic for Cardiovascular Surgery, University Hospital, Zurich Raemistrasse 100, 8091 CH-Zurich, Switzerland, Tel: +41 4463456 25; Fax: +41 4463456 08; E-mail: simon philipp.hoerstrup@usz.ch

Received August 17, 2015; Accepted September 17, 2015; Published September 24, 2015

Citation: Frese L, Sanders B, Beer GM, Weber B, Driessen-Mol A, et al. (2015) Adipose Derived Tissue Engineered Heart Valve. J Tissue Sci Eng 6: 156 doi:10.4172/2157-7552.1000156

Copyright: ( 2015 Frese L, et al. This is an open-access article distributed under the terms of the Creative Commons Attribution License, which permits unrestricted use, distribution, and reproduction in any medium, provided the original author and source are credited. 
cardiomyocytes and endothelial cells, sparked interest to develop them for future cell-based therapy such as heart valve engineering. MSCs are commonly isolated from the bone marrow and represent a great cell source for tissue engineering of living heart valves mainly due to their wide availability $[14,16,20,21]$. However, adult bone marrow derived MSCs are suboptimal for clinical use due to the required highly invasive donation procedure and the decline in both their proliferation and differentiation potential with increasing senescence. In turn, adipose derived stem cells (ADSCs) represent a promising alternative cell source of mesenchymal origin [22] with comparable differentiation potential. Additionally, the ease of repeated accessibility to subcutaneous adipose tissue and simple isolation procedures define their superiority as alternative clinical cell source. Since human ADSCs have not been previously exploited for the generation of Tissue Engineered Heart Valves (TEHV), this study investigated their suitability as and performance on TEHV scaffolds.

\section{Materials and Methods}

\section{Extraction of fat tissue and isolation of adipose derived stem cells}

Extraction of fat tissue: Human ADSCs were isolated using the adipose tissue of patients undergoing plastic surgery $(n=20)$. Samples were retrieved following procedures approved by the local ethics committee (KEK-ZH-2010-0476/0).

To harvest the fat tissue, liposuction was performed using the tumescent technique. This technique is used to loosen the fat cells from the connective tissue and especially to reduce the risk of bleeding. Tumescent fluid was injected into the surgical area (basic tumescent solution: $1000 \mathrm{ml} \mathrm{0.9 \%} \mathrm{NaCl}, 1 \mathrm{ml}$ Kenacort A 10, $12.5 \mathrm{ml} \mathrm{NaHCO}, 1$ $\mathrm{ml}$ of 1:1000 epinephrine, $50 \mathrm{ml}$ lidocaine $2 \%$ ) and left there for at least 30 minutes. Next, blunt Mercedes-cannulas ( $3 \mathrm{~mm}$ in diameter) were inserted into the fatty tissue and an excess of adipose tissue was aspirated into a glass-container with a vacuum of $-80 \mathrm{kP}$. The tumescence solution was allowed to settle in the collection container allowing for the removal of fat tissue supernatant without centrifugation.

Isolation of adipose derived stem cells: ADSCs were isolated and prepared as previously described by Digirolamo [23]. Briefly, the extracted adipose tissue was collected into a $50 \mathrm{ml}$ Falcon tube and digested at $37^{\circ} \mathrm{C}$ on a shaker $(180 \mathrm{rpm})$ for 45 minutes with $1 \mathrm{mg} / \mathrm{ml}$ collagenase Type A (Roche). The digested sample was then filtered through a $40 \mu \mathrm{m}$ nylon cell strainer. The mononuclear cell fraction was isolated by density gradient separation (Ficoll-PaqueTM Plus, Amersham Pharmacia Biotech) using standardized protocols [2426]. The separated mononuclear cell fraction was cultured in growth medium (Dulbecco's Modified Eagle Medium, DMEM, Sigma), supplemented with $2 \mathrm{mM}$ L-glutamine, $50 \mathrm{U} / \mathrm{mL}$ penicillin, $50 \mu \mathrm{g} /$ $\mathrm{mL}$ streptomycin and $10 \%(\mathrm{v} / \mathrm{v})$ of a selected batch of heat-inactivated Fetal Calf Serum (FCS, Gibco) at $37^{\circ} \mathrm{C}$ in a humidified atmosphere $\left(5 \% \mathrm{CO}_{2}\right)$. After 24 hours, the non-adherent cells were discarded and adherent cells were washed gently with medium and cultured for $\sim 14$ days. Growth medium was replaced twice per week.

\section{Characterization of expanded ADSC}

Expression profile of ADSC: ADSC phenotype was determined based on the presence of the mesenchymal stem cell antigens CD44 (Santa Cruz Biotechnologies) and CD73, CD90, CD166 (all Biolegend), as well as on the absence of the hematopoietic stem cell markers CD34 (Immuno Tools) and CD45 (Biolegend). Isolated cells were fixed with $4 \%$ paraformaldehyde and then incubated with the primary antibodies as specified above. Primary antibodies were detected with Cy-2-conjugated affinity-purified goat-anti-mouse antibodies (Jackson Immunoresearch Laboratories Inc.). The high-affinity filamentous actin (F-actin) probe Alexa 546 phalloidin as well as the nuclear counter stain DAPI (4,6-Diamidino-2-Phenylindole, Sigma) were used to counterstain cells (Invitrogen, Life Technologies). Negative controls were included by omitting the primary antibodies. Analysis was carried out using an inverted fluorescence microscope equipped with a CCD camera (Leica Microsystems AG). Image processing was performed using the Leica Application Suite processing software (Leica Microsystems AG)

For quantitative characterization of the ADSC surface antigen expression profile, flow cytometric analysis was performed using the primary and secondary monoclonal antibodies described above using a FACSCalibur (BD Biosciences) and appropriate scatter gating. \$Per sample $10^{4}$ events were acquired.

ADSC differentiation in vitro: To induce differentiation into adipocytes and osteocytes, ADSC were plated at a density of $1000 \mathrm{cells} / \mathrm{cm}^{2}$. For adipogenic differentiation, ADSC were differentiated with 10\% DMEM (see above) supplemented with dexamethasone (1 $\mu \mathrm{M})$, insulin $(10 \mu \mathrm{g} / \mathrm{mL})$, indomethacin $(120 \mu \mathrm{M})$ and 3-Isobutyl-1methylxanthine (IBMX, $0.5 \mathrm{mM}$ ).

The osteogenic induction medium contained DMEM supplemented with $60 \mu \mathrm{M}$ ascorbic acid, $10 \mathrm{mM} \beta$-glycerophosphate, $0.1 \mathrm{M}$ dexamethasone, $2 \mathrm{mM} \mathrm{L}$-glutamine, penicillin, streptomycin and $15 \%$ FCS.

The chondrogenic differentiation was evaluated in $15 \mathrm{~mL}$ conical tubes with $2 \times 10^{5}$ cells/ $\mathrm{mL}$ in DMEM medium supplemented with 2 $\mathrm{mM}$ L-glutamine, $1 \% \mathrm{FCS}, 10 \mathrm{ng} / \mathrm{mL}$ TGF- $\beta, 50 \mu \mathrm{M}$ ascorbic acid and $0.5 \mu \mathrm{g} / \mathrm{mL}$ insulin.

To induce endothelial differentiation, ADSCs were exposed to basal medium (EBMTM-2, Cambrex), containing Vascular Endothelial Growth Factor (VEGF), Human Fibroblast Growth Factor (hFGF), human recombinant long R3 Insulin-Like Growth Factor-1 (R-3IGF-1), Human Epidermal Growth Factor (hEGF), Gentamycin and Amphotericin (GA-1000), hydrocortisone, heparin, ascorbic acid, and $5 \%$ FCS. All induction media, summarized in Table 1, were replaced three times a week.

\begin{tabular}{|c|c|c|l|}
\hline Condition & Medium & Serum & Supplements \\
\hline Control & DMEM & $10 \%$ & none \\
\hline Adipogenic & DMEM & $10 \%$ & dexamethasone $(1 \mu \mathrm{M})$, insulin $(10 \mu \mathrm{g} / \mathrm{mL})$, indomethacin (120 M), 3-Isobutyl-1-methylxanthine (IBMX, 0.5 mM) \\
\hline Osteogenic & DMEM & $15 \%$ & $60 \mu \mathrm{M}$ ascorbic acid, $10 \mathrm{mM} \beta$-glycerophosphate, $0.1 \mu \mathrm{M}$ dexamethasone, \\
\hline Chondrogenic & DMEM & $1 \%$ & $10 \mathrm{ng}$ TGF- $\beta, 50 \mu \mathrm{M}$ ascorbic acid and $0.5 \mu \mathrm{g} / \mathrm{mL}$ insulin. \\
\hline Endothelial & EBMTM-2 & $5 \%$ & $\begin{array}{l}\text { vascular endothelial growth factor (VEGF), human fibroblasts growth factor (hFGF), human recombinant long insulin-like } \\
\text { growth factor-1 (R-3-IGF-1), human epidermal growth factor (hEGF), gentamycin and amphotericin (GA-1000), hydrocortisone, } \\
\text { heparin, ascorbic acid }\end{array}$ \\
\hline
\end{tabular}

Table 1: Medium compositions for differentiation of human adipose derived stem cells. 
Histology: The adipogenic, osteogenic and chondrogenic differentiation cultures were harvested after 21 days washed in PBS and fixed in $4 \%$ formalin before further histological analysis.

To detect the lipid vacuoles after adipogenic stimulation, cells were stained with Oil Red-O (3 mg/mL, Sigma). Calcium deposits arising during osteogenic differentiation were identified with $2 \%$ Alizarin Red S ( $\mathrm{pH} 4.2$, Fluka). Chondrogenic cultures were embedded in paraffin and sectioned at $5 \mu \mathrm{m}$ thickness. For histological evaluation of cartilage-specific proteoglycans, sulfated glycosaminoglycans (GAG) were visualized with $0.1 \%$ Toluidine blue (Sigma-Aldrich) in $1 \%$ sodium borate. In addition, ADSCs were analyzed for their endothelial differentiation potential using a tube formation assay. For this purpose $1.5 \times 10^{4}$ cells were seeded on a 96-well-plate coated with $80 \mu$ l Matrigel $\mathbb{Z}$ (BD Biosciences) and photographs depicting capillary tube formation were taken after $10 \mathrm{~h}$ and $24 \mathrm{~h}$ of incubation.

\section{Tissue engineering of heart valves}

Fabrication of heart valve scaffolds: The trileaflet heart valve scaffolds $(n=11)$, were produced from nonwoven polyglycolic acid meshes (PGA) with a thickness of $1.0 \mathrm{~mm}$ and a density of $70 \mathrm{mg} / \mathrm{cm}^{3}$ (Cellon). The scaffold was integrated into a self-expandable nitinol stent with an outer diameter of $30 \mathrm{~mm}$ (pfm AG) by sewing the scaffold molds onto the inner surface of the stent struts. Then, the scaffold-stentconstruct was coated by dipping them into the biologically derived and rapidly degradable biopolymer poly-4-hydroxybutyrate $(\mathrm{P} 4 \mathrm{HB}$, 1, 75\%, Tepha Inc.) in Tetrahydrofuran (THF, Fluka). After solvent evaporation, physical bonding of adjacent fibers and continuous coating was achieved. After evaporation of the THF, the produced heart valve construct was sterilized with ethylene oxide. The solvent was allowed to evaporate to reduce any toxic reaction to the cells before the scaffold was washed twice in PBS. Prior to cell seeding the scaffolds were incubated in tissue engineering (TE)-medium, DMEM growth medium listed above additionally supplemented with $0.1 \%$ FCS, $1 \%$ GlutaMax, $1 \%$ Penicillin-streptomycin and L-ascorbic acid 2-phosphate $(0.25 \mathrm{mg} / \mathrm{mL}$; Sigma-Aldrich) overnight.

Seeding of heart valves: For seeding onto the PGA/P4HB scaffold ADSC were diluted to a final concentration of $1.5 \times 10^{6} \mathrm{cells} / \mathrm{cm}^{2}$ in fibrin glue. To ensure homogeneous distribution throughout the scaffold the cells were first re-suspended in the thrombin component (10 IU, Sigma) and then quickly and thoroughly mixed with the fibrinogen component (10 $\mathrm{mg}$ protein, Sigma) and finally applied onto the scaffold construct.

Cultivation of the heart valves: After seeding, the heart valves were placed into a diastolic pulse duplicator system, previously described in detail [27]. This strain-based conditioning approach uses dynamic strains for cultivation of the TEHV with an additional continuous perfusion loop $(4 \mathrm{~mL} / \mathrm{min})$ to ensure a closed system. The leaflets were exposed to dynamic strains by applying increasing transvalvular pressure differences. After 5 days of culture with only perfusion and no transvalvular pressure differences, the system started with $3 \mathrm{~mm} \mathrm{Hg}$, increased up to $15 \mathrm{~mm} \mathrm{Hg}$ in the 4 following days and remained at that pressure until the end of the culture (day 28). TE-medium was replaced every 4 days.

Endothelialization of the TEHVs: After 4 weeks of culturing, TEHVs $(n=3)$ were endothelialized with $0.2 \times 10^{6}$ ADSC derived endothelial like cells per $\mathrm{cm}^{2}$ scaffold. Subsequently, TEHVs were further kept under dynamic culture conditions for another 48 hours in endothelial differentiation medium to ensure adequate cell attachment.
Thereafter, heart valves were harvested from the bioreactor system and analyzed accordingly.

\section{Analysis of tissue engineered heart valves}

Histological and immunohistochemical staining: For qualitative evaluation, representative samples of the cultivated TEHVs were fixed with $4 \%$ formalin, embedded in paraffin and cut into $5 \mu \mathrm{m}$ sections. To assess the tissue composition, the slides were stained with HaematoxylinEosin, Masson-Trichrome, Elastica-van-Gieson and von Kossa.

To determine the potential alteration of the seeded cells after cultivation, the slides were immunohistochemically analyzed using specific antibodies for vimentin, alpha smooth muscle actin (a-SMA, Dako) and the endothelial marker CD31 (Biolegend). Primary antibodies were detected by use of Diaminobenzidine (DAB, Histochemistry Kit, Molecular Probes).

Scanning electron microscopy: To evaluate the ultra-structural morphology of cells growing in the PGA/P4HB matrix, representative TEHV tissue samples were analyzed by Scanning Electron Microscopy (SEM). Tissue samples were fixed in $2 \%$ (v/v) glutaraldehyde with $0.1 \%$ cacodylate $\left(\mathrm{P}^{\mathrm{H}}\right.$ 7.3). After preparation, samples were sputtered with gold and investigated using a Zeiss Supra 50 VP Microscope (Zeiss).

Extracellular matrix production: To determine the major tissue structures responsible for native valve function, Extracellular Matrix (ECM) production was assessed by biochemical assays. To deduce the cell number on the scaffold, the content of total Deoxyribonucleic Acid (DNA) was analyzed as an indirect indicator. For measuring DNA amounts, the Hoechst dye method [28] was used and DNA content inferred from a standard curve prepared from calf thymus DNA (Sigma). The amount of produced collagen structures was determined by analyzing hydroxyproline (HYP) and sulfated glycosaminoglycan (GAG) content. HYP content was determined from lyophilized samples with a modified version of the protocol described by Huszar et al. [29] with trans-4-hydroxy-L-proline (Sigma) as standard. Sulphated GAG content was colorimetrically calculated using a chondroitin-6-sulfate from shark cartilage (Sigma) as standard [30]. The DNA, GAG and HYP content was normalized to the mg of dry tissue weight and standardized to native tissue.

Biomechanical analysis: The mechanical properties of the ADSC TEHV samples were analyzed with a biaxial tensile tester (BioTester, 5 $\mathrm{N}$ load cell; CellScale, Waterloo, Canada) in combination with LabJoy software (V8.01, CellScale). Two square samples of $36 \mathrm{~mm}^{2}$ each were symmetrically cut from one ADSC TEHV leaflet, taking into account the radial and circumferential orientation. Sample thickness was measured prior to testing. Samples were mounted onto the biaxial tensile tester, resulting in an effective test surface area of $12.25 \mathrm{~mm}^{2}$. A custom programmed protocol was stretching the sample equally biaxial in both radial and circumferential direction up to $30 \%$ strain at a strain rate of $1.66 \%$ per second. After stretching, the sample recovered directly back to $0 \%$ strain at a strain rate of $1.66 \%$ per second, followed by a rest cycle of 54 seconds. Prior to measuring the final stresses, the sample was preconditioned for 5 cycles. A high order polynomial curve was fitted through each individual data set in both radial and circumferential direction. The stiffness of the tissue was represented by the tangent modulus and was calculated as the slope from the tangent to the fitted polynomial curve at $30 \%$ strain.

\section{Statistical analysis}

Biochemical measurements and quantitative biomechanical data 
Citation: Frese L, Sanders B, Beer GM, Weber B, Driessen-Mol A, et al. (2015) Adipose Derived Tissue Engineered Heart Valve. J Tissue Sci Eng 6: 156. doi: $10.4172 / 2157-7552.1000156$

A
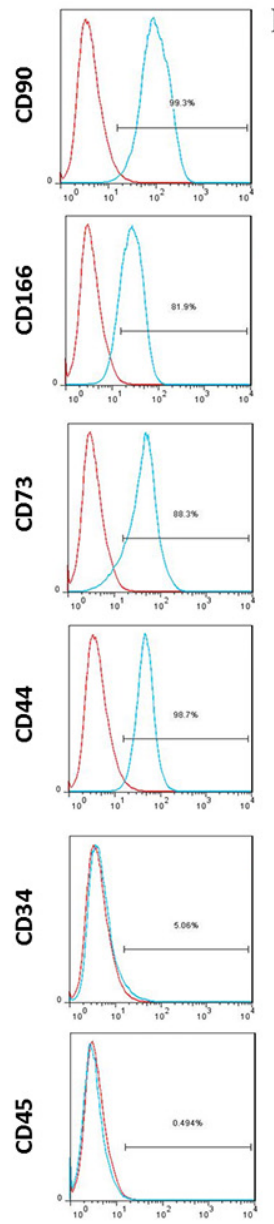

B
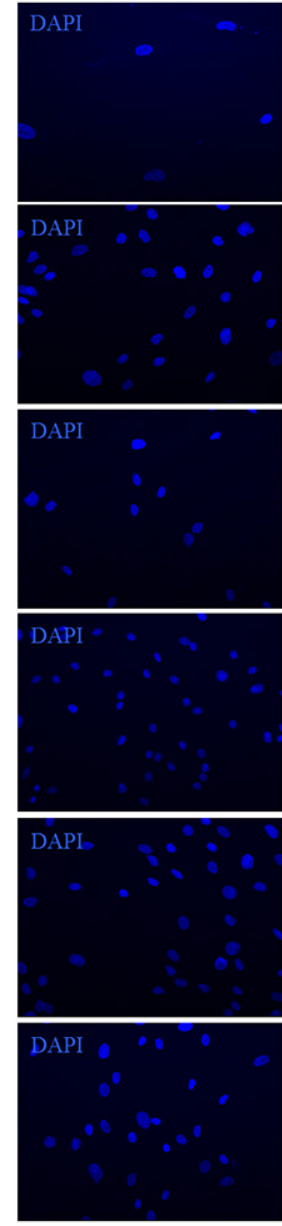
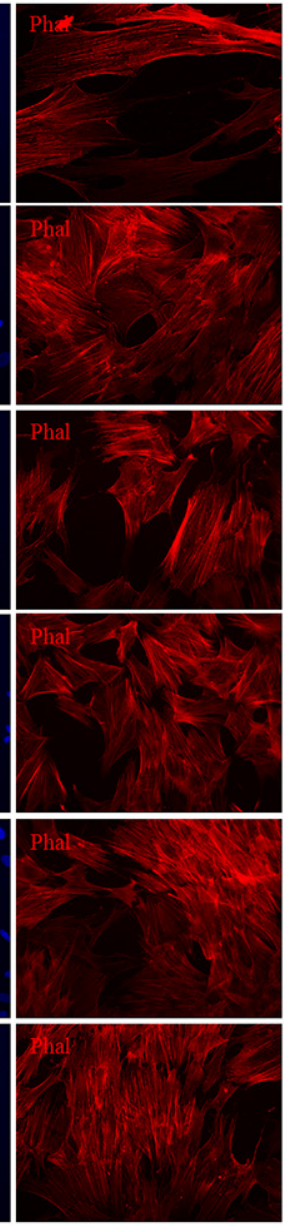
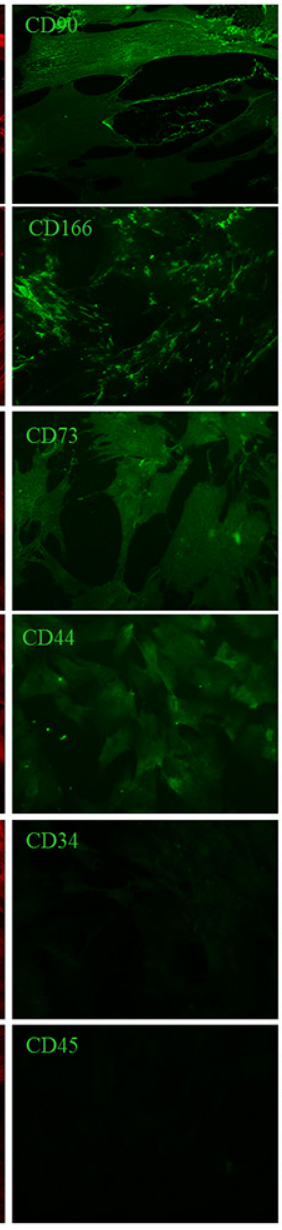
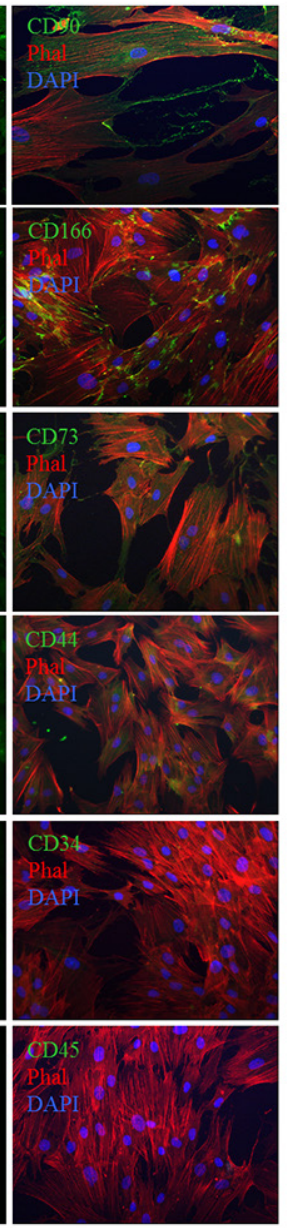

Figure 1: Expression profile of human adipose derived stem (ADSC). Flow cytomtery analysis revealed ADSC to be positive for CD166, CD90, CD73 and CD44, but negative for hematopoietic surface markers CD34 and CD45 (A). The immunofluorescence staining supported these results (B). The cells were stained with DAPI (blue) to identify the nuclei of the cells and with phalloidin to show the actin filament of the cells (red). The series of the CD proteins were stained in green. The three staining are merged in the last column.
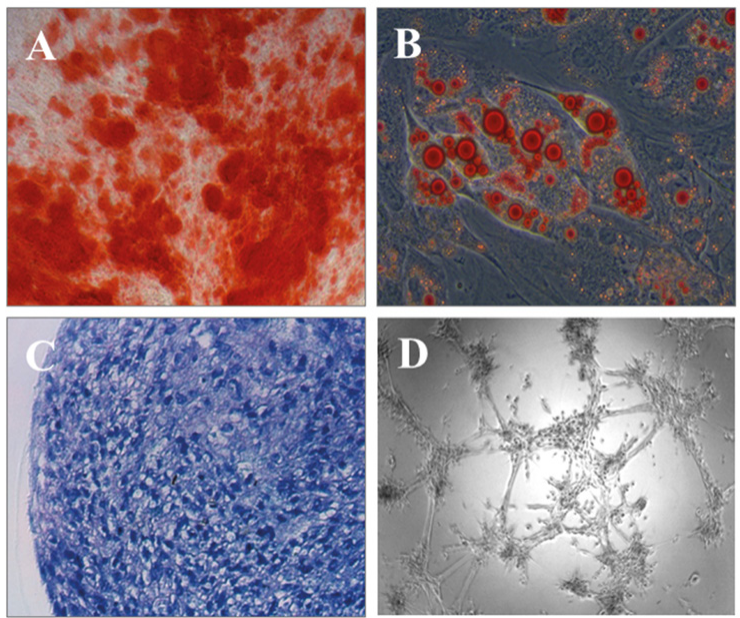

Figure 2: Differentiation assays. Cell differentiation of human adipose derived stem cells along the osteogenic (A), adipogenic (B), chondrogenic (C) and endothelial (D) pathways were detectedfollowing stainings with Alizarin Red $S$

(A), Oil red (B) and Toluidine blue (C). The endothelial like differentiation was demonstrated by the tube formation assay (D). are represented as mean \pm standard deviation. Paired t-tests were performed to test for differences between ECM group means (SPSS17.0, IBM, Somers, NY, USA).

\section{Results}

\section{Morphology and phenotype of adipose derived stem cells}

In this study, a cell population of mesenchymal origin obtained from human adipose fat tissue was examined concerning the multilineage potential. Human adipose tissue was obtained by liposuction $(n=20)$ from female patients of $49 \pm 8$ years of age. Approximately $0.5 \times 10^{6}$ mononuclear cells/g tissues were isolated independent of source type and subsequently cultured under standard conditions (10\% DMEM). In culture the cells attached to the bottom of the culture flask and assumed a fibroblast-like morphology. This morphology was maintained through repeated subcultures under expansion conditions; no other cell morphology was observed. During the subsequent 4 passages an average doubling time of 1.5 days was observed (data not shown). Neither source type, age nor body mass index (BMI) influenced the population doubling rate. 

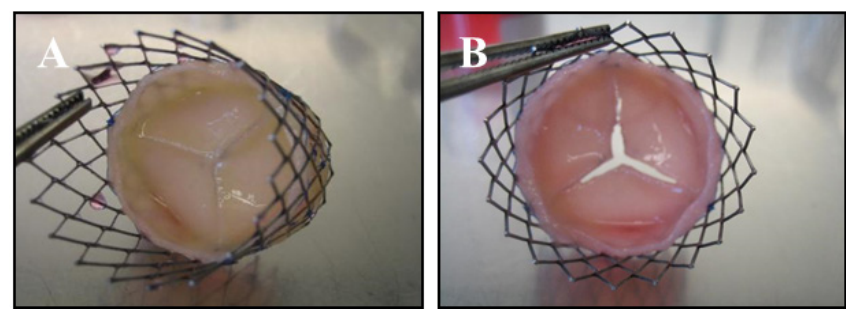

Figure 3: Macroscopic analysis of the tissue engineered heart valve based on adipose derived stem cells after 4 weeks of cultivation in the strain bioreacto system: Tissue engineered heart valve integrated in the Nitinol stent $(A)$. After dissection of the merged TE leaflets $(B)$ slight retraction of the leaflets revealed.

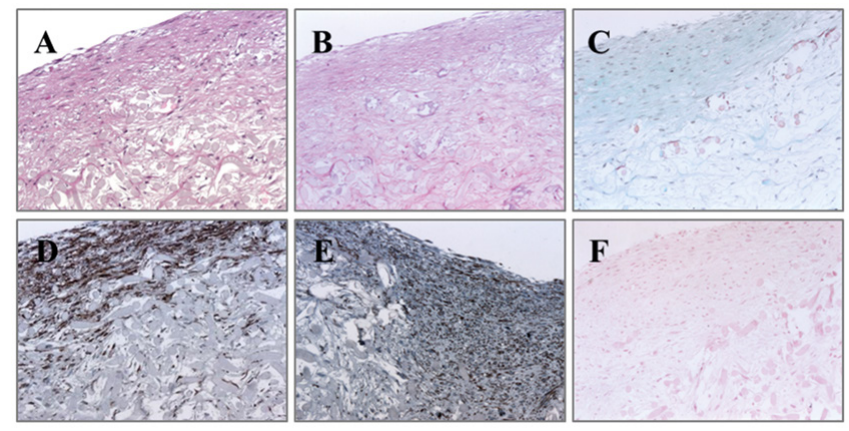

Figure 4: Microscopic analysis of the tissue engineered leaflets: The histological staining's (A: HE, B: Elastica van Gieson, C: Masson Goldner, D: alpha smooth muscle actin, E: Vimentin, F: von Figure Legend Kossa) of the tissue engineered heart valve leaflets showed a good cell distribution $(A)$, well developed outer layers but less cellularity in the inner part as well as a good extracellular matrix formation (B). After in vitro conditioning no elastic fibres (C) were detectable. The samples showed a pronounced a-SMA positive laye (D) and vimentin positive cells were detectable (E). Also no calcification was detectable after in vitro cultivation $(F)$.
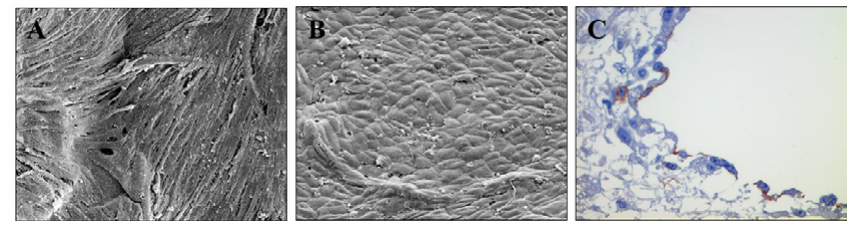

Figure 5: Endothelialisation: The ultra-structural analysis using SEM showed a densely covered surface of the tissue engineered heart valve leaflets and spindle shaped cells when seeded with human adipose derived stem (ADSC) (A). In contrast endothelial structures were visible after coating with ADSC derived endothelial-like cells (B). This superficial endothelial cell lining were also confirmed by the immuno-histological detection of the endothelial marker CD31 (C).

\section{Characterization of expanded ADSC}

Samples were analyzed by flow cytometry using the specific combination of mesenchymal stem cell surface markers to determine ADSC composition quantitatively. The analysis revealed ADSC to be positive for CD166 (73.8 $\pm 5.5 \%)$, CD90 (98.0 \pm 0.4\%), CD73 (91.0 \pm $0.5 \%)$ and CD44 (98.8 $\pm 0.2 \%)$, but negative for hematopoietic surface markers CD34 $(4.4 \pm 1.5 \%)$ and CD45 $(0.4 \pm 0.3 \%)$ (Figure 1A). The immunofluorescence staining supported these results (Figure 1B). The cells kept their stem cell character up to passage 5 under proliferation conditions (10\% DMEM).

Multilineage capacity of ADSC was then asserted using adipogenic, osteogenic, chondrogenic as well as endothelial-like differentiation assays with lineage specific induction factors (Table 1). Calcium
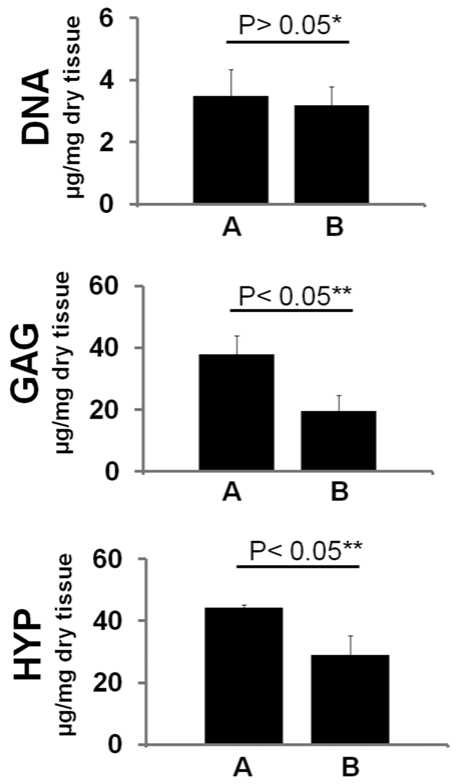

Figure 6: Extracellular matrix of the tissue engineered (TE) leaflets: The contents of DNA glycosaminoglycanes (GAG) and hydroxyprolines (HYP) in the TE leaflets (B column) were compared with native leaflet tissue (A column). (n.s.: non-significant; * significant for $\mathrm{P}=0.05$-level).

deposits and lipid vacuoles were detected 3 weeks after induction using Alizarin Red S and Oil Red-O staining, and revealed that ADSC had differentiated toward the osteogenic and adipogenic lineages, respectively (Figure $2 \mathrm{~A}$ and $2 \mathrm{~B}$ ).

ADSC initially grown in a monolayer were also cultivated in $3 \mathrm{D}$ spheres for 3 weeks, which is known to facilitate chondrogenesis [31]. Toluidin blue staining confirmed the production of cartilaginous matrix and hence the chondrogenic phenotype (Figure 2C). Differentiation of ADSC into functional endothelial like cells was investigated by performing a tube formation assay. The observed tube formation after 10 hours was comparable to freshly isolated endothelial cells from human umbilical cord (Figure 2D).

\section{Analysis of tissue engineered heart valve leaflets}

Macroscopic appearance: TEHV based on PGA/P4HB were seeded with human adult ADSC and cultivated using diastolic pulse duplicator systems to evaluate the cellular behavior on 3D formation [27]. This system mimics the diastolic phase in a closed leaflet culture by applying pressure, which acts on the surface of the leaflets resulting in tissue straining. The macroscopy of the ADSC-TEHV presented intact TEHVs with smooth and shiny tissue formation and homogeneous thickness after 4 weeks of cultivation (Figure 3A). However, dissection of the merged TE leaflets after culture revealed slight retraction (Figure $3 B)$.

Histological and immunohistochemical stainings and scanning electron microscopy: Microstructural features of representative tissue samples of the ADSC derived TE leaflets were analyzed both by histological and immunochemical staining procedures (Figure 4) as well as by scanning electron microscopy (Figure 5). Haematoxylin Eosin staining demonstrated appropriate tissue formation with welldeveloped outer layers and little cellularity in the inner part of the TEHVs (Figure 4A). Furthermore, effective tissue formation with collagen fibers was shown in Masson Goldner (Figure 4C) staining 

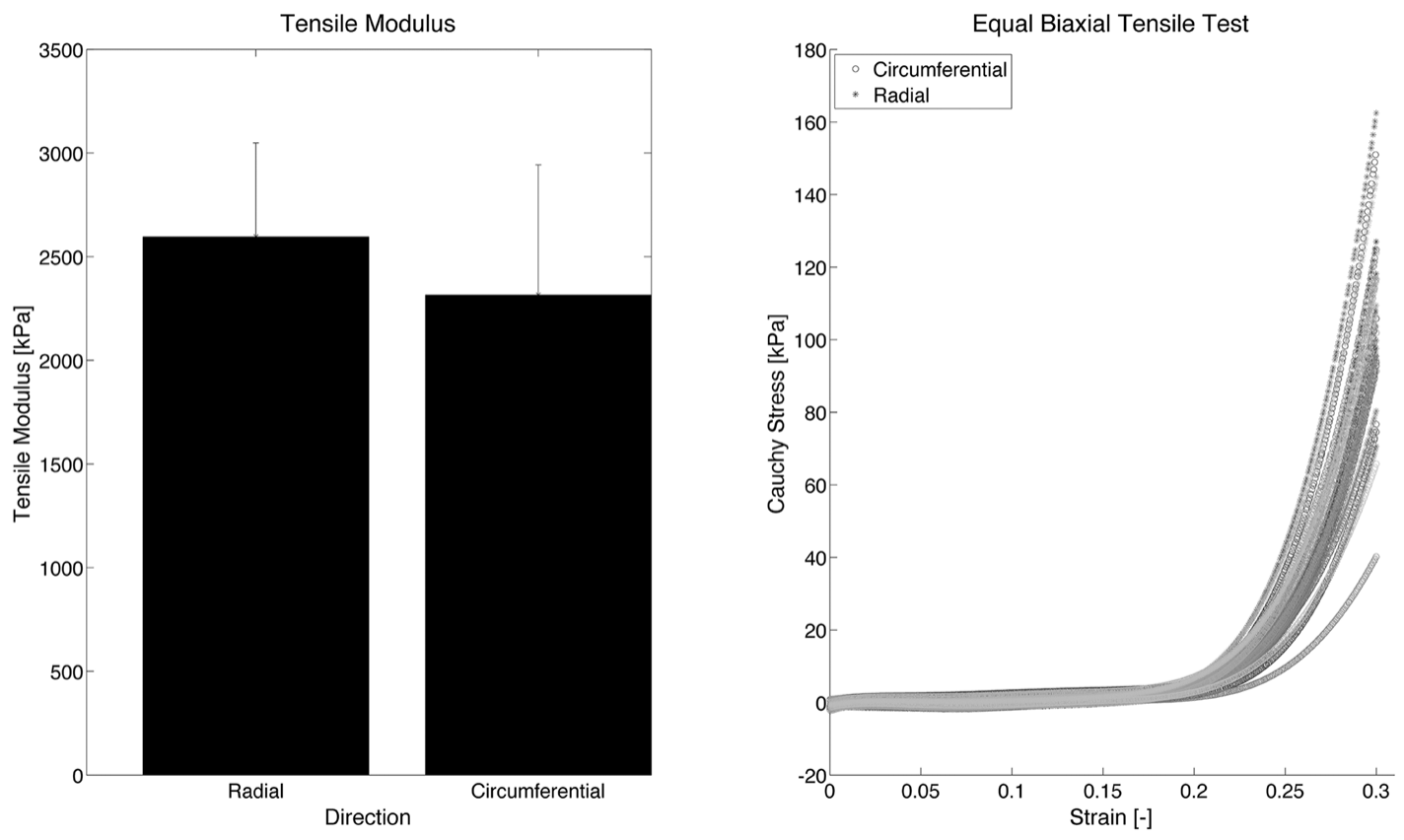

Figure 7: Equal biaxial tensile results of ADSC TEHV leaflets. Left: the tangent modulus of the samples at $30 \%$ strain in both radial and circumferential direction. Right: the equal biaxial tensile curves after preconditioning in both radial and circumferential direction, up to a strain of $30 \%$. (n.s.: non-significant).

and a relatively high amount of $\alpha$-smooth muscle actin ( $\alpha$-SMA) was detected within the neo-tissue (Figure 4D). The intermediate filament protein vimentin, predominantly found in cells of mesenchymal origin, was expressed throughout the entire TEHV tissue (Figure 4E). However, elastic fibers were undetectable by the Elastica van Gieson staining after the in vitro conditioning in the bioreactor system (Figure 4B). The ultra-structural analysis using SEM showed a densely covered surface of the TEHV leaflets with extracellular matrix elements and spindle shaped cells when seeded with ADSC (Figure 5A). Moreover after additional coating with ADSC derived endothelial-like cells, a cobble stone pattern on the tissue surface was observed (Figure 5B). This superficial endothelial cell lining was also confirmed by the positive detection of the endothelial marker CD31 on the surfaces of the TE leaflets (Figure 5C).

ECM components: Next, neo-tissue ECM composition of the ADSC derived TEHV leaflets was biochemically analyzed using HYP, GAG and DNA assays. TEHV leaflets showed on average of $28.9 \mu \mathrm{g}$ HYP per mg dry tissue, which corresponds to about $65 \%$ of native heart valve tissue, implying that the collagen content is significantly lower in tissue engineered when compared to native heart valves $(\mathrm{p}<0.05)$. The GAG and DNA content amounted to $19.7 \mu \mathrm{g}$ and 3.1 $\mu \mathrm{g}$ per dry tissue, respectively. These values correspond to $50 \%$ GAG $(\mathrm{p}<0.05)$ and $88 \%$ DNA $(\mathrm{p}>0.05)$ when compared to native valve tissue (Figure 6).

Biomechanical behavior: Equal biaxial tensile tests were executed up to a strain of $30 \%$ to investigate the biomechanical behavior of the ADSC TEHVs. The stress-strain curves and calculated tangent moduli are shown in both radial and circumferential direction in Figure 7. The tangent moduli are $2.66 \pm 0.43 \mathrm{MPa}$ and $2.45 \pm 0.51 \mathrm{MPa}$ in radial and circumferential direction, respectively. No significant difference in tissue stiffness can be observed between both radial and circumferential direction. Therefore, isotropy of the material may be assumed.

\section{Discussion}

As a novel and clinically interesting cell source in regenerative medicine, adipose tissue seems to be a rich source of multipotent adipose tissue-derived mesenchymal stem cells. In order to evaluate ADSC as an alternative cell source for the production of TEHV, adult ADSC were isolated from fat suction from plastic surgery and characterized. The cells exhibited the characteristics of mesenchymal stem cells regarding their differentiation capacity into the osteogenic, adipogenic, chondrogenic and endothelial-like lineage. Furthermore, the stem cell specific combination of surface markers was detectable by immunohistochemical staining's as well as by flow cytometry. According to current literature the anatomical site of the adipose tissue does not affect the total number of viable cells that can be obtained from the subcutaneous fatty tissue $[32,33]$. Compared with mesenchymal stem cells from bone marrow biopsies, ADSC show also no statistically significant correlation between ADSC stem cell quality, proliferation capacity and the patient's age [34]. Additionally, ADSC implicate an equal differentiation potential into cells and tissues of mesenchymal origin [35]. However, the proportion of ADSC (hip/thigh) is much higher than the frequency of MSC in bone marrow, which is lower than $0,001 \%-0,01 \%$ [36]. Taken together, fat tissue is a promising and clinical highly relevant source for isolating mesenchymal stem cells in large quantities with comparable cell quality.

Accordingly, clinical applications for cell therapy and tissue engineering using ADSC are highly promising and have already been used successfully in a variety of clinical trials, especially in tissue reconstruction. The first clinical trials were already initiated at the beginning of the $21^{\text {st }}$ century. There the feasibility and safety of autologous ADSC transplantation were tested, e.g. in peripheral nerve repair [37], treatment of Crohn's disease fistulas [38], osteogenesis imperfecta [39], bladder diseases, urethral sphincter dysfunction associated with birth trauma and hormonal deficiency as well as the 
regeneration of bladder tissues [40]. Further studies substantiated the therapeutic potential of ADSC by transplanting them in a setting of chronic heart failure [41] or Acute Myocardial Infarction (AMI). After cell transplantation into the myocardial scar tissue in rabbit and porcine models, ADSC formed cardiac islands and vessel-like structures, induced angiogenesis and improved cardiac function with no report of potentially severe arrhythmias $[42,43]$. The APOLLO trial, a "firstin-man", prospective, double blind, randomized and placebo-controlled trial, demonstrated the safety and feasibility of ADSC transplantation in patients with acute myocardial infarction [43].

In the field of cardiovascular surgery, Taylor et al. in 2011 were the first to report that ADSC respond to mechanical stimulations/stress in a similar manner as valve interstitial cells, e.g. by secreting collagen. It was demonstrated that stretching increased the incorporation of hydroxyproline in ADSC, which was followed by the enhanced production of collagen and elastin crosslinks. This observation represents a fundamental mechanism which is essential to maintain the load capacity of leaflets and allows therewith valve functionality [44]. In the present study, after four weeks bioreactor cultivation, TEHV based on ADSC consisted on average of $29 \mu \mathrm{g}$ collagen (HYP) per mg dry tissue, which is $65 \%$ of the values of native valves. Previous studies that used e.g. amniotic fluid derived stem cells for TEHV production, only reached up to $3 \mu \mathrm{g}$ HYP (2.5\% of the value of native tissue) [13]. Collagen is the most copious protein in cardiovascular tissue and is essential to provide tensile strength in an organized scaffold. Also, the ECM component elastin in the TEHV is of particular importance for the biomechanical behavior of the valves [45]. Without the mechanical component elastin, the mechanical behavior of native valve cusp will be altered, primarily by reducing the valve's extensibility and increasing their stiffness in the radial direction [46]. Using the histological Elastica van Gieson staining, an elastin network was not detectable after in vitro conditioning in the bioreactor system in the present study. However this in vitro observation is only of minor impact due to elastin production after transplantation which occurred in in vivo studies already 20 weeks after implantation [17].

From the biomechanical analyses it cannot be concluded if these valves are functional under pulmonary conditions. However, the tissue stiffness range is in the right order of magnitude [47,48], which suggests that the TEHVs may perform appropriately in vivo.

The necessity of endothelialization of tissue engineered heart valves is still highly controversial. Endothelialization of grafts can improve their long term patency and prevent thrombogenesis [49]. However, in vitro endothelialization of grafts involves multiple additional procedures, for instance donation of patient specific tissue for isolation of endothelial cells. In vivo studies showed that implantation of nonendothelialized TEHV resulted in almost confluent endothelialization already after $4-8$ weeks in vivo $[16,48,50,51]$. However, using ADSC for tissue engineering would enable the endothelialization after differentiation of the cells in the presence of vascular endothelial growth factor without requiring any surgical harvesting of additional patientspecific tissues. In the present study, the endothelial surface layer on the TEHV wall as well as on the valvular leaflets was detected by the immunohistochemical staining with the endothelial marker CD31 as well as by ultra-structural analysis (SEM).

After separation of the TE leaflets (which is a prerequisite before implantation), retraction of valve leaflets occurred, which might affect functionality of the valves. This phenomenon, which was also observed in TEHV based on other cell types [52,53], might be the result of the complete relaxation of the stent after harvest or of the relatively high amount of $\alpha$-SMA. Elimination of cellular components (decellularization) of the TEHV might strongly reduce this problem, without altering the collagen structure or tissue strength [47]. As a result, the decellularised TEHV (dTEHV) would not show any retraction of leaflets after separation. Moreover, decellularization would enable on-the-shelf storage of the TEHV and simplify the logistic of TEHV implantations. Prior to implantation, dTEHV could be loaded with autologous less contractile cells, endowed with a reservoir of soluble factors that can exert paracrine effects on other cells ingrowth resulting in remodelling stimulation.

\section{Conclusion}

The aim of the present study was to evaluate the feasibility of autologous Adipose Derived Stem Cells (ADSC), obtained through plastic surgery fat harvesting in combination with the fast degrading scaffold material $\mathrm{PGA} / \mathrm{P} 4 \mathrm{HB}$ for the in vitro generation of tissue engineered heart valves.

The simple and minimally invasive surgical procedure, the easy and repeatable access to the subcutaneous adipose tissue, and the uncomplicated enzyme-based isolation procedures make this tissue source of MSC most attractive for clinical application. Therefore, ADSC represent an alternative source of autologous adult stem cells that can be obtained repeatedly in large quantities under local anesthesia with a minimum of donor-site morbidity.

TEHV based on human adult ADSC after cultivation using strain bioreactors showed a good and vital cell distribution throughout the whole tissue structure. Furthermore, a mechanically stable isotropic matrix with collagen production was built, producing a tissue stiffness in the right order of magnitude for heart valve applications [47]. These preliminary results indicate that ADSC represent an auspicious cell type for the production of tissue engineered heart valves, in particular due to their capacity to synthesize and remodel extracellular matrix, and to respond to biophysical and biochemical stimuli.

However, despite the promising outcomes, the biologic mechanisms that underlie the therapeutic success of stem cell transplantations are still unknown [54]. The successful generation of functional TEHV based on ADSC clearly demands further experiments including work on animal models before successful clinical application. Our data will be of key relevance for promoting the efficiency of stem cell therapy.

\section{Acknowledgment}

The authors thank Ladina Ettinger, Kathi Kämpf and the Center for Microscopy and Image Analysis, especially Klaus Marquardt for their excellent technical support.

This work was financially supported by European Union's Seventh Framework Programme (FP7/2007-2013) under grant agreement number 242008 (LifeValve).

\section{References}

1. Pibarot P, Dumesnil JG (2009) Prosthetic heart valves: Selection of the optimal prosthesis and long-term management. Circulation 119: 1034-1048.

2. Yacoub MH, Takkenberg JJ (2005) Will heart valve tissue engineering change the world? Nat Clin Pract Cardiovasc Med 2: 60-61.

3. Rahmani B, Tzamtzis S, Ghanbari H, Burriesci G, Seifalian AM (2012) Manufacturing and hydrodynamic assessment of a novel aortic valve made of a new nanocomposite polymer. J Biomech 45: 1205-1211.

4. George I, Shah JN, Bacchetta M, Stewart A (2009) Stentless bioprosthesis in a valved conduit: implications for pulmonary reconstruction. Ann Thorac Surg 88: 2022-2024

5. Brown JW, Ruzmetov M, Vijay P, Rodefeld MD, Turrentine MW (2007) Right 
ventricular outflow tract reconstruction with a polytetrafluoroethylene monocusp valve: a twelve-year experience. J Thorac Cardiovasc Surg 133: 1336-1343.

6. Yuan SM, Mishaly D, Shinfeld A, Raanani E (2008) Right ventricular outflow tract reconstruction: Valved conduit of choice and clinical outcomes. J Cardiovasc Med (Hagerstown) 9: 327-337.

7. Kowert A, Vogt F, Beiras-Fernandez A, Reichart B, Kilian E (2012) Outcome after homograft redo operation in aortic position. Eur $\mathrm{J}$ Cardiothorac Surg 41 : 404-408.

8. Boethig D, Thies WR, Hecker $H$, Breymann $T$ (2005) Mid term course after pediatric right ventricular outflow tract reconstruction: a comparison of homografts, porcine xenografts and Contegras. Eur J Cardiothorac Surg 27: $58-66$

9. Cebotari S, Tudorache I, Ciubotaru A, Boethig D, Sarikouch S, et al. (2011) Use of fresh decellularized allografts for pulmonary valve replacement may reduce the reoperation rate in children and young adults: Early report. Circulation, 124 S115-S123.

10. Mohammadi S, Belli E, Martinovic I, Houyel L, Capderou A, et al. (2005) Surgery for right ventricle to pulmonary artery conduit obstruction: risk factors for further reoperation. Eur J Cardiothorac Surg 28: 217-222.

11. Schmidt D, Mol A, Neuenschwander S, Breymann C, Gössi M, et al. (2005) Living patches engineered from human umbilical cord derived fibroblasts and endothelial progenitor cells. Eur J Cardiothorac Surg 27: 795-800.

12. Schmidt D, Mol A, Breymann C, Achermann J, Odermatt B, et al. (2006) Living autologous heart valves engineered from human prenatally harvested progenitors. Circulation 114: I125-131.

13. Schmidt D, Achermann J, Odermatt B, Breymann C, Mol A, et al. (2007) Prenatally fabricated autologous human living heart valves based on amniotic fluid derived progenitor cells as single cell source. Circulation 116: 164-170.

14. Kadner A, Hoerstrup SP, Tracy J, Breymann C, Maurus CF, et al. (2002) Human umbilical cord cells: A new cell source for cardiovascular tissue engineering. Ann Thorac Surg 74: S1422-1428.

15. Kadner A, Zund G, Maurus C, Breymann C, Yakarisik S, et al. (2004) Human umbilical cord cells for cardiovascular tissue engineering: A comparative study. Eur J Cardiothorac Surg 25: 635-641.

16. Weber B, Scherman J, Emmert MY, Gruenenfelder J, Verbeek R, et al. (2011) Injectable living marrow stromal cell-based autologous tissue engineered heart valves: first experiences with a one-step intervention in primates. Eur Heart 32: $2830-2840$

17. Hoerstrup SP, Sodian R, Daebritz S, Wang J, Bacha EA, et al. (2000) Functional living trileaflet heart valves grown in vitro. Circulation 102: Ill44-49.

18. Hoerstrup SP, Cummings Mrcs I, Lachat M, Schoen FJ, Jenni R, et al. (2006) Functional growth in tissue-engineered living, vascular grafts: follow-up at 100 weeks in a large animal model. Circulation 114: I159-166.

19. Mol A, Rutten MC, Driessen NJ, Bouten CV, Zünd G, et al. (2006) Autologous human tissue-engineered heart valves: prospects for systemic application. Circulation 114: I152-158.

20. Hoerstrup SP, Kadner A, Melnitchouk S, Trojan A, Eid K, et al. (2002) Tissue engineering of functional trileaflet heart valves from human marrow stromal cells. Circulation, 106: I143-1150.

21. Schmidt D, Dijkman PE, Driessen-Mol A, Stenger R, Mariani C, et al.( 2010) Minimally-invasive implantation of living tissue engineered heart valves: a comprehensive approach from autologous vascular cells to stem cells. J Am Coll Cardiol, 56: 510-520

22. Zuk PA, Zhu M, Mizuno H, Huang J, Futrell JW, et al. (2001) Multilineage cells from human adipose tissue: implications for cell-based therapies. Tissue Eng 7: 211-228.

23. Digirolamo CM, Stokes D, Colter D, Phinney DG, Class R, et al. (1999) Propagation and senescence of human marrow stromal cells in culture: a simple colony-forming assay identifies samples with the greatest potential to propagate and differentiate. $\mathrm{Br} \mathrm{J}$ Haematol 107: 275-281.

24. Pittenger MF, Mackay AM, Beck SC, Jaiswal RK, Douglas R, et al. (1999) Multilineage potential of adult human mesenchymal stem cells. Science 284 143-147.

25. Zachar V, Rasmussen JG, Fink T (2011) Isolation and growth of adipose tissuederived stem cells. Methods Mol Biol 698: 37-49.
26. Baumgartner L, Arnhold S, Brixius K, Addicks K, Bloch W (2010) Human mesenchymal stem cells: Influence of oxygen pressure on proliferation and chondrogenic differentiation in fibrin glue in vitro. J Biomed Mater Res A 93: 930-940.

27. Mol A, Driessen NJ, Rutten MC, Hoerstrup SP, Bouten CV, et al. (2005) Tissue engineering of human heart valve leaflets: A novel bioreactor for a strain-based conditioning approach. Ann Biomed Eng 33: 1778-1788.

28. Cesarone CF, Bolognesi C, Santi L (1979) Improved microfluorometric DNA determination in biological material using 33258 Hoechst. Anal Biochem 100: 188-197.

29. Huszar G, Maiocco J, Naftolin F (1980) Monitoring of collagen and collagen fragments in chromatography of protein mixtures. Anal Biochem 105: 424-429.

30. Farndale RW, Buttle DJ, Barrett AJ (1986) Improved quantitation and discrimination of sulphated glycosaminoglycans by use of dimethylmethylene blue. Biochim Biophys Acta 883: 173-177.

31. Wu SC, Hsiao HF, Ho ML, Hung YL, Chang JK, et al. (2015) Suppression of discoidin domain receptor 1 expression enhances the chondrogenesis of adipose-derived stem cells. Am J Physiol Cell Physiol 308: C685-696.

32. Oedayrajsingh-Varma MJ, van Ham SM, Knippenberg M, Helder MN, KleinNulend J, et al. (2006) Adipose tissue-derived mesenchymal stem cell yield and growth characteristics are affected by the tissue-harvesting procedure. Cytotherapy 8: 166-177.

33. Smith P, Adams WP Jr, Lipschitz AH, Chau B, Sorokin E, et al. (2006) Autologous human fat grafting: Effect of harvesting and preparation techniques on adipocyte graft survival. Plast Reconstr Surg 117: 1836-1844.

34. Beane OS, Fonseca VC, Cooper LL, Koren G, Darling EM (2014) Impact of aging on the regenerative properties of bone marrow-, muscle-, and adiposederived mesenchymal stem/stromal cells. PLoS One 9: e115963.

35. Schäffler A, Büchler C (2007) Concise review: Adipose tissue-derived stroma cells--basic and clinical implications for novel cell-based therapies. Stem Cells 25: 818-827.

36. Pittenger MF, Mosca JD, McIntosh KR (2000) Human mesenchymal stem cells Progenitor cells for cartilage, bone, fat and stroma. Curr Top Microbiol Immuno 251: 3-11.

37. Kappos EA, Engels PE, Tremp M, Meyer Zu Schwabedissen M, di Summa P, et al. (2015) Peripheral Nerve Repair: Multimodal Comparison of the Long-Term Regenerative Potential of Adipose Tissue-Derived Cells in a Biodegradable Conduit. Stem Cells Dev.

38. García-Olmo D, García-Arranz M, Herreros D, Pascual I, Peiro C, et al. (2005)A phase I clinical trial of the treatment of Crohn's fistula by adipose mesenchymal stem cell transplantation. Dis Colon Rectum 48: 1416-1423.

39. Horwitz EM, Prockop DJ, Fitzpatrick LA, Koo WW, Gordon PL, et al. (1999) Transplantability and therapeutic effects of bone marrow-derived mesenchymal cells in children with osteogenesis imperfecta. Nat Med 5: 309-313.

40. Lin CS (2010) Advances in stem cell therapy for the lower urinary tract. World J Stem Cells 2: 1-4.

41. Ishida O, Hagino I, Nagaya N, Shimizu T, Okano T, et al. (2015) Adiposederived stem cell sheet transplantation therapy in a porcine model of chronic heart failure. Transl Res 165: 631-639.

42. Zhang DZ, Gai LY, Liu HW, Jin QH, Huang JH, et al. (2007) Transplantation of autologous adipose-derived stem cells ameliorates cardiac function in rabbits with myocardial infarction. Chin Med J (Engl) 120: 300-307.

43. Meliga E, Strem BM, Duckers HJ, Serruys PW (2007) Adipose-derived cells Cell Transplant 16: 963-970.

44. Colazzo F, Sarathchandra P, Smolenski RT, Chester AH, Tseng YT, et al. (2011) Extracellular matrix production by adipose-derived stem cells: Implications for heart valve tissue engineering. Biomaterials 32: 119-127.

45. Mol A, Smits Al, Bouten CV, Baaijens FP (2009) Tissue engineering of heart valves: Advances and current challenges. Expert Rev Med Devices 6: 259-275.

46. Lee TC, Midura RJ, Hascall VC, Vesely I (2001) The effect of elastin damage on the mechanics of the aortic valve. J Biomech 34: 203-210.

47. Dijkman PE, Driessen-Mol A, Frese L, Hoerstrup SP, Baaijens FP (2012) Decellularized homologous tissue-engineered heart valves as off-the-shelf alternatives to xeno- and homografts. Biomaterials 33: 4545-4554. 
Citation: Frese L, Sanders B, Beer GM, Weber B, Driessen-Mol A, et al. (2015) Adipose Derived Tissue Engineered Heart Valve. J Tissue Sci Eng 6: 156. doi:10.4172/2157-7552.1000156

Page 9 of 9

48. Weber B, Dijkman PE, Scherman J, Sanders B, Emmert MY, et al. (2013) Offthe-shelf human decellularized tissue-engineered heart valves in a non-human primate model. Biomaterials 34: 7269-7280.

49. Thébaud NB, Pierron D, Bareille R, Le Visage C, Letourneur D, et al. (2007) Human endothelial progenitor cell attachment to polysaccharide-based hydrogels: A pre-requisite for vascular tissue engineering. J Mater Sci Mater Med 18: 339-345.

50. Baraki H, Tudorache I, Braun M, Höffler K, Görler A, et al. (2009) Orthotopic replacement of the aortic valve with decellularized allograft in a sheep model. Biomaterials 30: 6240-6246

51. Driessen-Mo A, Emmert MY, Dijkman PE, Frese L, Sanders B, et al. (2014) Transcatheter implantation of homologous "off-the-shelf" tissue-engineered heart valves with self-repair capacity: Long-term functionality and rapid in vivo remodeling in sheep. J Am Coll Cardiol 63: 1320-1329.

52. Shinoka T, Breuer CK, Tanel RE, Zund G, Miura T, et al. (1995) Tissue engineering heart valves: Valve leaflet replacement study in a lamb model. Ann Thorac Surg 60: S513-516.

53. Syedain ZH LM, Johnson SL, Robinson PS, Ruth GR, Bianco RW, et al. (2011) Implantation of a tissue-engineered heart valve from human fibroblasts exhibiting short term function in the sheep pulmonary Artery. Cardiovasc Eng Technol 2: 101-112.

54. Cowan CM, Shi YY, Aalami OO, Chou YF, Mari C, et al. (2004) Adipose-derived adult stromal cells heal critical-size mouse calvarial defects. Nat Biotechnol 22: $560-567$ 